\title{
Modelling of three-reactor system for chemical looping hydrogen generation: identifying a suitable operating range
}

\author{
Zhipeng Xue ${ }^{1, *}$, Junfeng $X u^{2}$, Minmin Zhao ${ }^{2}$ \\ ${ }^{1}$ PH.D, Huadian Electric Power Research Institute, NO. 2 Xiyuan 9 Road, Xihu District, Hangzhou Zhejiang Province, 310030, China \\ ${ }^{2}$ ENGINEER, Huadian Electric Power Research Institute, NO. 2 Xiyuan 9 Road, Xihu District, Hangzhou Zhejiang Province, 310030, \\ China
}

\begin{abstract}
Chemical-looping hydrogen generation can produce hydrogen from fossils fuels with inherent separation of $\mathrm{CO}_{2}$. In this article, a novel compact fluidized bed is used for CLHG to solve the problem of low fuel gas conversion causing by thermodynamic limit. Based on the compact fluidized bed, a modelling of threereactor system for CLHG process is built to study the operating range of this system. The results show that the low limit of the system temperature is $650^{\circ} \mathrm{C}$, or else unexpected reaction will occur in reactors. The system can achieve heat-integrated by mixing a certain amount of inert support into oxygen carrier and adjusting a suitable temperature different among reactors. Moreover, an operational range of the oxygen carrier recycle rate between 6 and $8 \mathrm{~mol} \mathrm{Fe} / \mathrm{mol} \mathrm{CH}_{4}$ is recommended for more extensive operating region and relative higher $\mathrm{CH}_{4} / \mathrm{H}_{2}$ ratio can be obtain. Finally, a fitting formula described the operating range of this system is proposed to provide a reference for the experiment and simulation in further work.
\end{abstract}

\section{Introduction}

Carbon dioxide that originates from the combustion of fossil fuel is one of the most important greenhouse gases that contribute to the global warming. [1] Hydrogen, as a clean energy carrier, has the potential to become a major solution of the problems of climate change in the foreseeable future. However, in order not to weaken the inherent environmental and climatic cleanliness of hydrogen in the whole process, the production steps of primary energy also need to be cleaner. [2] At present, hydrogen is produced predominantly by steam reforming of natural gas, thermal cracking of natural gas, partial oxidation of heavy fractions, or coal gasification. The main drawbacks of those techniques are the emissions of $\mathrm{CO}_{2}$ and the energy penalties used for $\mathrm{CO}_{2}$ capture that increase the production costs. Therefore, it is beneficial to develop innovative technologies for hydrogen generation while simultaneously reduce the cost of $\mathrm{CO}_{2}$ capture. Recently, the hydrogen production technologies based on chemical-looping combustion (CLC) have received more and more attention.

CLC is a two-step combustion process with inherent $\mathrm{CO}_{2}$ separation, which can reduce the energy penalty for the separation of $\mathrm{CO}_{2}$ from a flue gas stream. The reactor system consists of two separate reactors, an air reactor and a fuel reactor. The essential oxygen is supplied by an oxygen carrier which transfers oxygen between the fuel reactor and air reactor.[3-6]

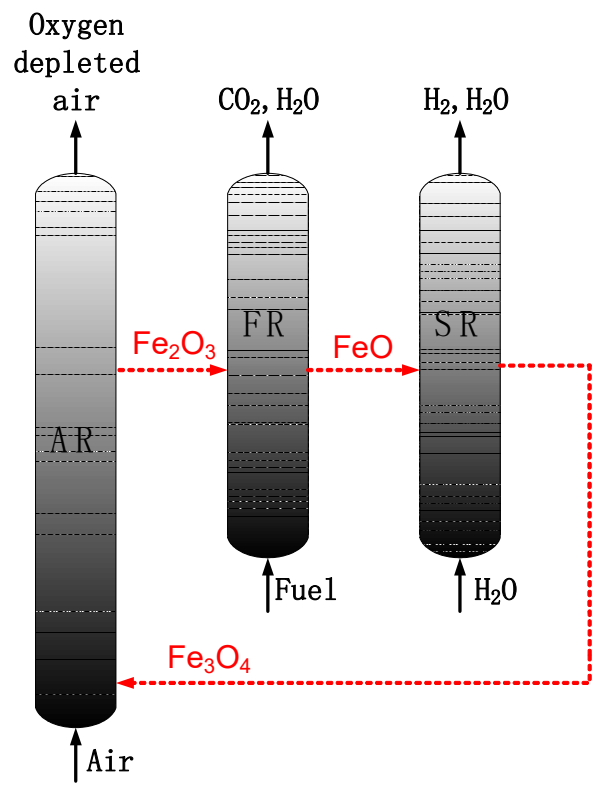

Fig.1. Conceptual scheme of chemical-looping hydrogen generation.

Chemical looping hydrogen generation (CLHG) is a novel hydrogen production technology based on CLC.

$\overline{{ }^{*} \text { Corresponding author: xuezhipeng@1 } 126 . c o m ~}$ 
Ideally, the advantage of this system is that pure hydrogen can be obtained with simultaneous capture $\mathrm{CO}_{2}$. Iron oxides are considered as one of the most suitable oxygen carrier for CLHG. The reactor system consists of three rectors: a fuel reactor (FR), a steam reactor (SR) and an air reactor (AR). The iron oxides transfer oxygen among reactors.

In the FR, hematite $\left(\mathrm{Fe}_{2} \mathrm{O}_{3}\right)$ is mostly reduced to wüstite $(\mathrm{FeO})$ by gaseous fuels. The reaction in the FR can be summarized as follows

$$
\mathrm{C}_{x} \mathrm{H}_{y}+\left(2 x+\frac{y}{2}\right) \mathrm{Fe}_{2} \mathrm{O}_{3} \rightarrow x \mathrm{CO}_{2}+\frac{y}{2} \mathrm{H}_{2} \mathrm{O}+2\left(2 x+\frac{y}{2}\right) \mathrm{FeO}
$$

The gaseous outlet stream is composed of water vapor and $\mathrm{CO}_{2}$. After condensation of water the $\mathrm{CO}_{2}$ can subsequently be compressed and transported to suitable storage facilities.

In the $\mathrm{SR}$, the reduced $\mathrm{FeO}$ reacted with the steam according to the following reactions:

$$
3 \mathrm{FeO}+\mathrm{H}_{2} \mathrm{O} \rightarrow \mathrm{Fe}_{3} \mathrm{O}_{4}+\mathrm{H}_{2}
$$

The outlet stream from SR contains mainly $\mathrm{H}_{2}$ and water vapor. After the water condensation, almost pure $\mathrm{H}_{2}$ stream is obtained. Yet the iron oxides can only be oxidized to $\mathrm{Fe}_{3} \mathrm{O}_{4}$, thus further oxidized to more stable iron oxides is happened in the AR. The main reaction in the AR can be written as follows:

$$
4 \mathrm{Fe}_{3} \mathrm{O}_{4}+4 \mathrm{~N}_{2}+\mathrm{O}_{2} \rightarrow 6 \mathrm{Fe}_{2} \mathrm{O}_{3}+4 \mathrm{~N}_{2}
$$

$\mathrm{Fe}_{3} \mathrm{O}_{4}$ is fully oxidized back to the $\mathrm{Fe}_{2} \mathrm{O}_{3}$ by air, then $\mathrm{Fe}_{2} \mathrm{O}_{3}$ is returned to the FR for a new cycle. The AR exit stream contains $\mathrm{N}_{2}$ and some excess $\mathrm{O}_{2}$.

The major advantage of this system is that pure $\mathrm{H} 2$ and $\mathrm{CO}_{2}$ can be obtained respectively without extra energy for the gas separation. Compared to well-known technologies, such as auto-thermal reforming or fired tubular reforming, additional $\mathrm{CO}_{2}$ separation cost, $\mathrm{H}_{2}$ purification and water gas shift are avoided. Thus, there is no energy penalty in the separation and no costs associated with gas separation equipment and operation. [7]

Some approaches have been reported for the process simulation of CLHG. P. Chiesa et al. [8] proposed a threereactor chemical looping process for hydrogen production from natural gas using iron oxides as the oxygen carrier. In their study, a discussion of two plant configurations has presented, and a comparison with "steam reforming" plants is also carried out. The results showed that, compared to available technology, the CLHG show similar efficiency but much better environmental performance, because the $\mathrm{CO} 2$ capture is virtually complete, and this process deserves substantial research and development activities in the near future. C Jason, et al. [9] simulated a CLHG system in conjunction with a steam-coal gasification process, and the system show considerable promise for the successful coupling with a chemical looping system with a gasifier. L Fan and G Nirmal et al. [10-11] investigated iron based on a chemical looping process for direct coal gasification-coal direct chemical looping (CDCL) and a syngas chemical looping (SCL) combustion system for hydrogen production and $\mathrm{CO}_{2}$ separation. Simulation studies showed very high conversion efficiency from coal to hydrogen compared with SCL.

Although many researchers have proved the feasibility of CHLG, the CHLG still has difficulty in application to practical situation due to some limitations, in particular the low conversion of fuel gas in FR, owing to the limits of thermodynamic equilibrium. Many works have indicated that the conversion of $\mathrm{CO}$ and $\mathrm{H}_{2}$ is low when reducing $\mathrm{Fe}_{2} \mathrm{O}_{3}$ to $\mathrm{FeO}$ or $\mathrm{Fe}$ in a single step. [12-15] J Yang et al. [16] investigated the chemical looping hydrogen generation with direct reduction of iron oxides by coal char in fluidized bed. Results showed that a considerable amount of CO cannot be oxidized to $\mathrm{CO}_{2}$ in the reduction, which may reduce the efficiency of $\mathrm{CO}_{2}$ capture in CLHG.

Some researchers focus on the reactor design to make up for the deficiency causing by iron oxides. G Puneet et al.[17] proposed that countercurrent moving-bed reactor can help solve the problem of low fuel gas conversion of FR. In countercurrent moving-bed reactor, the fuel gas continuously contacts metal oxide particles of higher oxygen content as it itself gets oxidized.

W Xiang et al. [12] presented a novel fuel reactor concept, compact fluidized bed, to increase the fuel gas conversion. The principle of compact fluidized bed can be best described as: the fuel gas first reduces $\mathrm{Fe}_{3} \mathrm{O}_{4}$ to $\mathrm{FeO}$ (Eq.4-6), then the unconverted fuel gas in those irreversible reactions is fully converted to $\mathrm{CO}_{2}$ and $\mathrm{H}_{2} \mathrm{O}$ by participating in the irreversible reaction $\mathrm{Fe}_{2} \mathrm{O}_{3}$ reduce to $\mathrm{Fe}_{3} \mathrm{O}_{4}$ (Eq. 7-9).

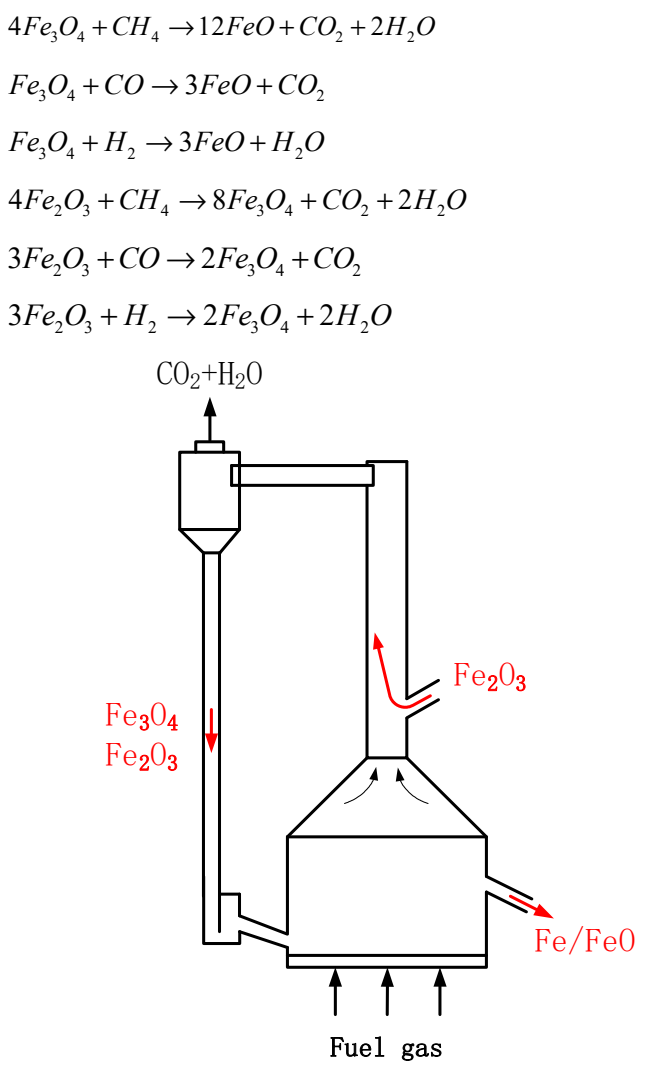

Fig. 2. Schematic diagram of compact fluidized bed. 
Fig. 2 shows the schematic diagram of compact fluidized bed. The compact fluidized bed comprised of two parts: upper fuel reactor and lower fuel reactor. The lower fuel reactor has a wider cross-section than that of the upper fuel reactor. Thus, the lower and the upper fuel reactor can operate respectively as a bubbling fluidized bed and a fast fluidized bed through selecting a suitable cross-section. The solids inlet is located at the bottom of the upper fuel reactor. $\mathrm{Fe}_{2} \mathrm{O}_{3}$ is induced from the solids inlet, and then thrown upwards by the high-speed gas. In the upper fuel reactor, Part of $\mathrm{Fe}_{2} \mathrm{O}_{3}$ is reduced to $\mathrm{Fe}_{3} \mathrm{O}_{4}$ in the upper fuel reactor by the unconverted fuel gases from the lower fuel reactor. After that, the $\mathrm{Fe}_{3} \mathrm{O}_{4}$ and the unreacted $\mathrm{Fe}_{2} \mathrm{O}_{3}$ pass through the cyclone, downcomer and loop seal continuously then enter the lower fuel reactor, where the $\mathrm{Fe}_{3} \mathrm{O}_{4}$ and the unreacted $\mathrm{Fe}_{2} \mathrm{O}_{3}$ are further reduced to $\mathrm{FeO}$ by fuel gas.[18] In sum, in the compact fluidized bed, the fuel gas can be completely oxidized to $\mathrm{CO}_{2}$ and $\mathrm{H}_{2} \mathrm{O}$ while simultaneously reduced $\mathrm{Fe}_{2} \mathrm{O}_{3}$ to $\mathrm{FeO}$.

Based on the compact fluidized bed, a three-reactor fluidized bed system for CLHG was designed and a cold flow model of this system has been built by Z Xue et al.[18] As can be seen from Fig. 3. The feasibility and the operating region of this reactor system from the hydrodynamic aspect have been studied. Results showed that the system can achieve continuous operation stability and reliability in a wide region. However, it is equally important to study the thermodynamic operating region of this system. Therefore, a modeling of three-reactor fluidized bed for CLHG with ASPEN Plus is introduced in this paper. A range of operating conditions has been simulated in order to ensure an operating region within which the system can be fully heat-integrated (i.e. with no external addition of heat required), whilst achieving satisfactory fuel gas conversion and hydrogen purity.

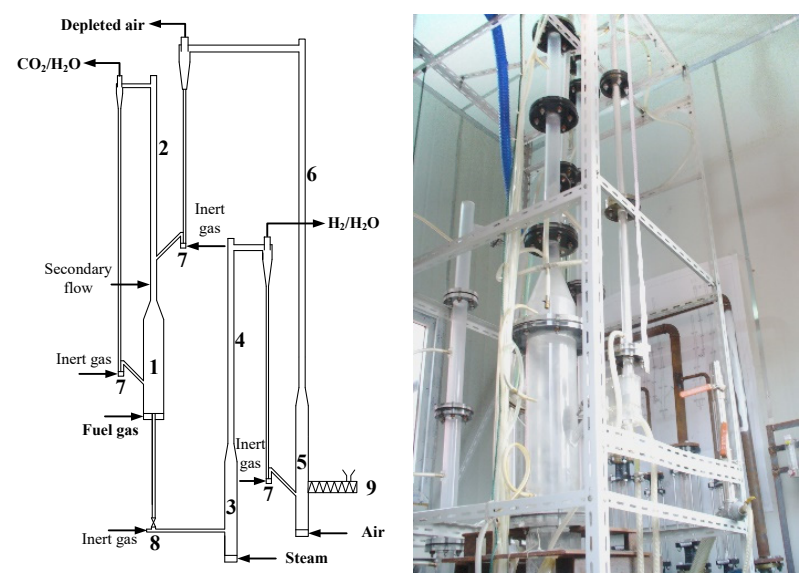

Fig.3. Design layout of the three-reactor system for CLHG.

\section{Model description}

Simulations were performed in aspen plus 11.1. The flowsheet for CLHG system, including FR1, FR2, SR and $\mathrm{AR}$ is presented in Fig.4. All reactors were calculated using RGibbs reactor blocks, which assumes chemical equilibrium based on Gibbs free energy minimization. The iron oxides show in Fig. 4 is merely indicative of the principal oxide likely to be present. The compact fluidized bed was modeled using FR1, FR2 and two separators. It can be seen that the exit gas of FR1 is separated by FR1 separator (FR1S) and then enters into FR2. Moreover, the solid production in FR2 is separated by FR2 separator (FR2S) and then enters into FR1.

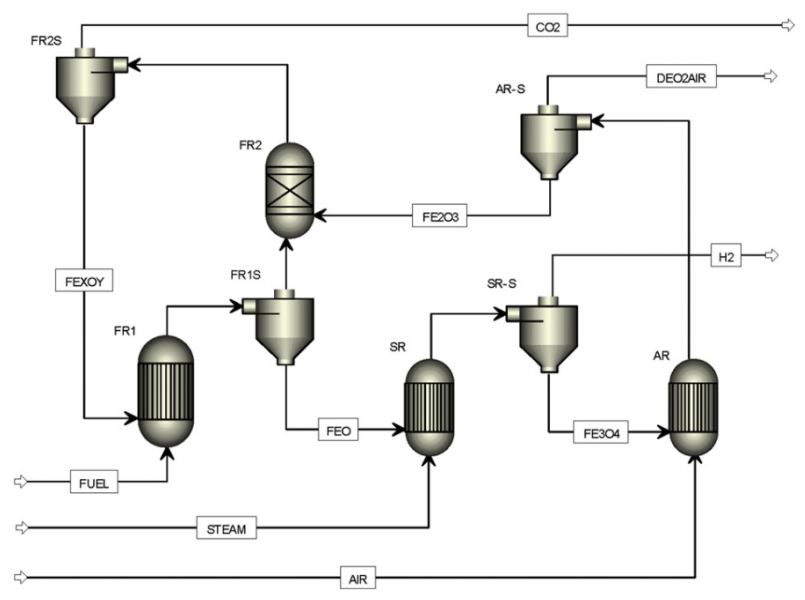

Fig.4. Aspen Plus flowsheet of a three-reactor system with two FR arrangements.

The temperatures of fuel and air stream were set at $250^{\circ} \mathrm{C}$, assuming the fuel and air stream were preheated by flue gas in gas preheater. To avoid the interference of other components on the results and to understand the mechanisms of this process, methane is the only component of fuel gas. The steam was assumed that obtained from steam turbine, and therefore, the temperature of steam was set at $500^{\circ} \mathrm{C}$. Moreover, A FORTRAN program was used in Aspen Plus to make sure that the flow rate of steam and air could be minimized on the premise of the reaction in SR and AR can reach thermodynamic equilibrium in any case. The thermodynamics data for various chemical species were obtained from Aspen Plus. The main parameters are summarized in Table. 1.

Table 1. the main parameters of the model.

\begin{tabular}{|l|l|}
\hline Parameter & Value \\
\hline Fuel type & methane \\
\hline Pressure (bar) & 1 \\
\hline Oxygen carrier & iron oxides \\
\hline Inert support & $\mathrm{FeAl}_{2} \mathrm{O}_{4}$ \\
\hline Fluidization gas in FR & methane \\
\hline Fluidization gas in $\mathrm{SR}$ & steam \\
\hline Fluidization gas in $\mathrm{AR}$ & air \\
\hline
\end{tabular}




\begin{tabular}{|l|l|}
\hline Temperature of methane $\left({ }^{\circ} \mathrm{C}\right)$ & 250 \\
\hline Temperature of steam $\left({ }^{\circ} \mathrm{C}\right)$ & 500 \\
\hline Temperature of air $\left({ }^{\circ} \mathrm{C}\right)$ & 250 \\
\hline Flow rate of methane $(\mathrm{mol} / \mathrm{sec})$ & 1 \\
\hline Flow rate of steam $(\mathrm{mol} / \mathrm{sec})$ & calculated by program \\
\hline Flow rate of air $(\mathrm{mol} / \mathrm{sec})$ & calculated by program \\
\hline
\end{tabular}

\section{Data evaluation}

For better comparison of the ratio of various chemical species, the flow rate of $\mathrm{CH}_{4}$ was set at $1 \mathrm{~mol} / \mathrm{sec}$. and the units about flow rate and heat release were defined base on the flow rate of $\mathrm{CH}_{4}$. For example, mol Fe/mol $\mathrm{CH}_{4}$ for oxygen carrier recycle rate and $\mathrm{kW} / \mathrm{mol} \mathrm{CH}_{4}$ for heat release in FR1. In addition, if the value of heat release is positive, the reactor is exothermic; if negative, the reactor is endothermic.

For the evaluation of the results, an important parameter, the $\mathrm{CO}_{2}$ yield, describes the conversion rate of fuel gas to $\mathrm{CO}_{2}$ after cooling the water vapor is calculated as

$$
\gamma_{\mathrm{CO}_{2}}=\frac{x_{\mathrm{CO}_{2}}}{x_{\mathrm{CO}_{2}}+x_{\mathrm{CH}_{4}}+x_{\mathrm{CO}}+x_{\mathrm{H}_{2}}}
$$

Where, xi is the molar flow of the species $\mathrm{i}$ exhausted from FR2.

Another two parameters describe the affinity of the reactions towards $\mathrm{H}_{2}, \mathrm{H}_{2} / \mathrm{CH}_{4}$ conversion rate and $\mathrm{H}_{2} / \mathrm{H}_{2} \mathrm{O}$ conversion rate

$$
\begin{gathered}
\gamma_{\mathrm{H}_{2} / \mathrm{CH}_{4}}=\frac{x_{\mathrm{H}_{2}}}{x_{\mathrm{CH}_{4}}} \\
\gamma_{\mathrm{H}_{2} / \mathrm{H}_{2} \mathrm{O}}=\frac{x_{\mathrm{H}_{2}}}{x_{\mathrm{H}_{2} \mathrm{O}}}
\end{gathered}
$$

\section{Results and discussion}

\subsection{Heat balance analysis}

Before considered the operating range of the whole system, it is necessary to ensure the reactions occurred in system is what we desire. Fig.5a, b, c and d respectively show the influence of the temperature of system on heat release of four reactors, solid components of inlet and outlet of FR1, gas components of inlet and outlet of FR2, and the flow rate of inlet steam and outlet $\mathrm{H}_{2}$ of SR. In order to avoid oxygen carriers carrying heat between the reactors, in this case, all the reactors operate at the same temperature. As can be seen from Fig.5a, the process can be divided into three phases from the trend of the curve.

For phase I, almost no reaction occurred in the FR1 and SR for the thermodynamic limit in this temperature region. This can also be confirmed from Fig.5a, b and c that almost no change on the quantity of heat and components in the FR1 and SR. However, in FR2, most of $\mathrm{CH} 4$ could only be oxidized to $\mathrm{CO}$ and $\mathrm{H}_{2}$ by $\mathrm{Fe}_{2} \mathrm{O}_{3}$. This process could be considered as an endothermic reaction and the $\mathrm{Fe}_{2} \mathrm{O}_{3}$ was fully reduced to $\mathrm{Fe}_{3} \mathrm{O}_{4}$, then passed through the FR1, SR and re-oxidized in the AR.

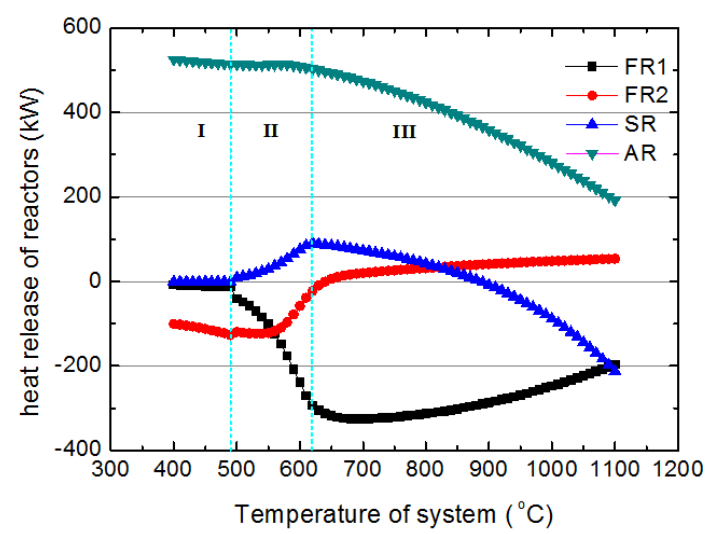

(a)

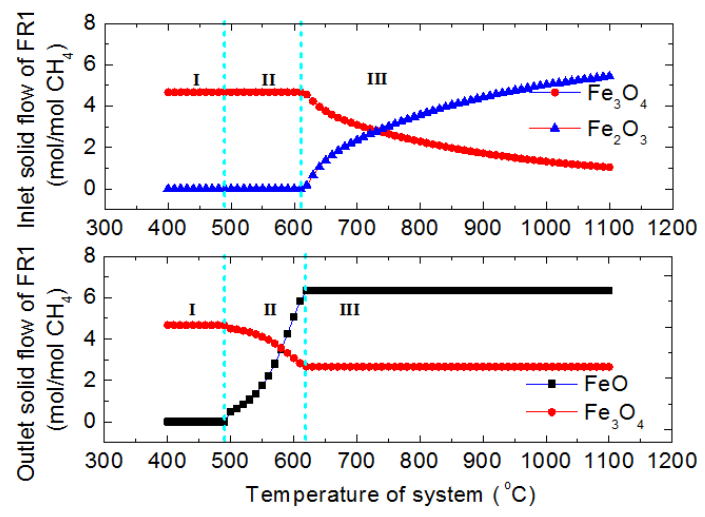

(b)
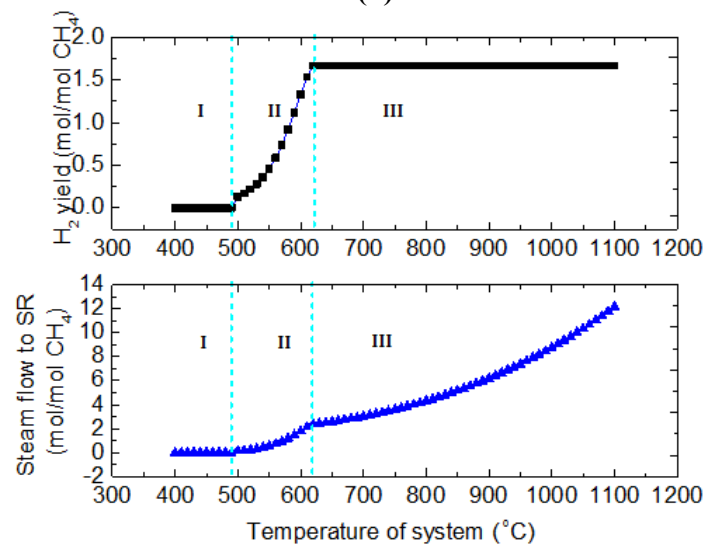

(c) 


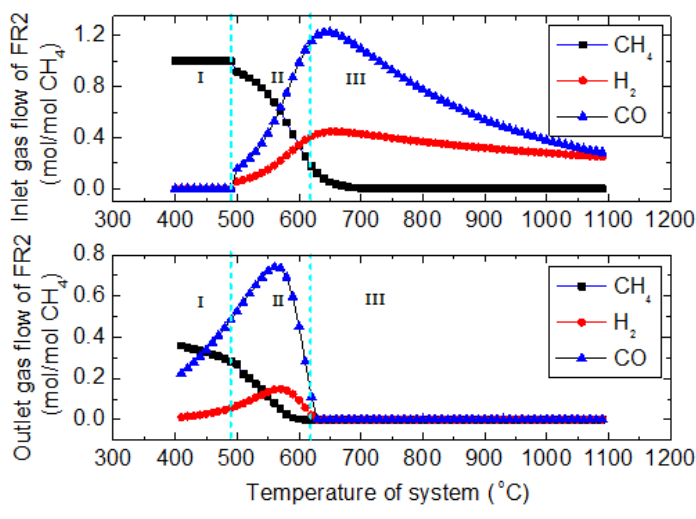

(d)

Fig.5. Heat and mass of four reactors as a function of temperature of system (a) heat release of reactors, (b) solid components of inlet and outlet of FR1, (c) gas components of inlet and outlet of FR2, (d) the flow rate of inlet steam and outlet $\mathrm{H}_{2}$ of SR.

For phase II, the heat absorption of the FR1 increased as the system temperature increased, this is a consequence of more $\mathrm{Fe}_{3} \mathrm{O}_{4}$ reduced to $\mathrm{FeO}$ in the FR1 as show in Fig. 5b. Simultaneously, the heat release in the SR increased, for more and more $\mathrm{FeO}$ produced from the FR1 came into the SR and took part in the exothermic reaction Eq. 2. In an addition, the heat release in the FR2 was relatively stable at first, then gradually increased to zero as the temperature of the system increased. This is because although the reducing gas is still excessive in the FR1, excessive degree of reducing gas is decreased, and thus the endothermic reaction Eq. 1 has gradually been replaced by the exothermic reaction Eq. 2.

Finally, in phase III, both the heat release in the AR and SR were decreased as the temperature of system increased. This is a consequence of the increase of sensible heat for air and steam. However, in FR1, the heat release increased as the temperature of system increased. This is a consequence of the increase of $\mathrm{Fe}_{2} \mathrm{O}_{3}$ came into the FR1, and thus the increase of the heat release from the exothermic reaction $\mathrm{Fe}_{2} \mathrm{O}_{3}$ reduced to $\mathrm{Fe}_{3} \mathrm{O}_{4}$.

Through the analysis above, it can be seen that only phase III can agree well with the process design. However, a suitable operating condition must meet the following criteria

(1) Excluding any water vapor present, the concentration of $\mathrm{CO}_{2}$ of converted reducing gas stream must be at least $99 \%$ pure.

(2) The mole fraction of the produced $\mathrm{H}_{2}$ stream must be at least $99 \%$ after condensing the water vapor.

(3) All the reactor must be exothermic to make sure the system can be operated without excess heat.

Apparently, as can be seen from Fig.5c and d, the phase III could meet only criteria (1) and (2). However, as an endothermic process, the FR1 cannot be operated without excess heat. This problem can be solved by mixing inert support into oxygen carrier. In addition, it can observed from Fig. 5d that for the thermodynamics equilibrium limit, the $\mathrm{H}_{2} / \mathrm{H}_{2} \mathrm{O}$ conversion rate decreased as the temperature of system increased. Which means more steam vapor was consumed and more quantity of heat was used to supply the sensible heat of steam vapor. Therefore, the lower and upper limit of the temperature of the SR was set at $650^{\circ} \mathrm{C}$ and $881^{\circ} \mathrm{C}$ separately.

\subsection{Influence of inert support recycle rate}

Apparently, inert support has almost no effect on $\mathrm{CO}_{2}$ and $\mathrm{H}_{2}$ yield. Therefore, the study in this section focus on the heat-integrate among reactors. The essential reaction heat for FR1 can be transported from exothermic reactors by inert support. Since the reaction in the AR is a highly exothermic process, it is more suitable to provide heat quantity to the FR1. A higher temperature of AR, compared with FR1, is necessary to supply the drive force for heat change. In addition, the FR2 and AR is designed as operating with the same temperature, and also for the SR and FR1, which can ensure the heat transfer occur only between the AR and FR1. For example, a typical operating case and main results are shown in Table. 2, the temperature of inert support was $870^{\circ} \mathrm{C}$ after leaving $\mathrm{AR}$, for both $\mathrm{AR}$ and FR2 was operating at $870^{\circ} \mathrm{C}$, the inert support passed through FR2 without heat transfer. And then enter into the FR1, where the inert support released heat by the drive force of temperature difference. After that, the temperature of inert support was reduced to $720^{\circ} \mathrm{C}$. Similarly, the inert supply passed through the SR without heat transfer and finally went back to the $\mathrm{AR}$. In the $\mathrm{AR}$, the temperature of inert support increased from $720^{\circ} \mathrm{C}$ to $870^{\circ} \mathrm{C}$ again, and the inert support can be used for a new cycle. The results shows that, satisfactory $\mathrm{CO}_{2}$ and $\mathrm{H}_{2}$ yield can be obtain in this case, and four reactors can achieve release heat simultaneously by selecting suitable inert support recycle rate and temperature difference between AR and FR1.

Table 2. Typical operating case and main results.

\begin{tabular}{|l|c|}
\hline Parameter & Value \\
\hline SR temperature $\left({ }^{\circ} \mathrm{C}\right)$ & 720 \\
\hline FR1 temperature $\left({ }^{\circ} \mathrm{C}\right)$ & 720 \\
\hline FR2 temperature $\left({ }^{\circ} \mathrm{C}\right)$ & 870 \\
\hline AR temperature $\left({ }^{\circ} \mathrm{C}\right)$ & 870 \\
\hline Steam temperature $\left({ }^{\circ} \mathrm{C}\right)$ & 500 \\
\hline CH4 temperature $\left({ }^{\circ} \mathrm{C}\right)$ & 250 \\
\hline Air temperature $\left({ }^{\circ} \mathrm{C}\right)$ & 250 \\
\hline
\end{tabular}




\begin{tabular}{|l|c|}
\hline $\mathrm{CH}_{4}$ molar flow $(\mathrm{mol} / \mathrm{sec})$ & 1 \\
\hline Air molar flow $(\mathrm{mol} / \mathrm{sec})$ & 5.8 \\
\hline Steam molar flow $(\mathrm{mol} / \mathrm{sec})$ & 3.9 \\
\hline Oxygen carrier flow rate $(\mathrm{mol} / \mathrm{sec})$ & 7 \\
\hline Inert support flow rate $(\mathrm{mol} / \mathrm{sec})$ & 8 \\
\hline Heat release of $\mathrm{FR} 1(\mathrm{~kW} / \mathrm{mol} \mathrm{CH} 4)$ & 50.91 \\
\hline Heat release of FR2 $\left(\mathrm{kW} / \mathrm{mol} \mathrm{CH}_{4}\right)$ & 37.99 \\
\hline Heat release of SR $\left(\mathrm{kW} / \mathrm{mol} \mathrm{CH}_{4}\right)$ & 68.36 \\
\hline Heat release of AR $\left(\mathrm{kW} / \mathrm{mol} \mathrm{CH}_{4}\right)$ & 26.69 \\
\hline $\mathrm{CO}_{2}$ yield $(\%)$ & $99.99 \%$ \\
\hline $\mathrm{H}_{2}$ yield $(\%)$ & $\sim 100 \%$ \\
\hline $\mathrm{H}_{2} / \mathrm{CH}_{4}$ conversion rate $(-)$ & 1.66 \\
\hline
\end{tabular}

\begin{tabular}{|l|l|l|l|l|}
\hline T1 & $4 \sim 30$ & 7 & $650 \sim 1100$ & $650 \sim 1000$ \\
\hline T2 & 6 & $2 \sim 12$ & $650 \sim 1100$ & $650 \sim 1000$ \\
\hline T3 & $4 \sim 40$ & $7 \sim 12$ & $650 \sim 1100$ & 650 \\
\hline T4 & $4 \sim 40$ & $7 \sim 12$ & $650 \sim 1100$ & 881 \\
\hline
\end{tabular}

Since both the $\mathrm{CO}_{2}$ and the $\mathrm{H}_{2}$ yield can meet the criteria (1) and (2), the operating region is determined by criteria (3) that if all the reactors are exothermic. Fig. 6 shows the operating region of the system as a function of inert support recycle rate, temperature of $\mathrm{AR}$ and FR1. The oxygen carrier recycle rate was held constant at $7 \mathrm{~mol} \mathrm{Fe} / \mathrm{mol} \mathrm{CH}_{4}$ and the detail of the operating parameters can reference T1 showed in Table 3. The points in Fig.6 represents all the reactors are exothermic, so the operating region can be represented by the area that formed by the operating points. Firstly, the results can agree well the discussed above that the temperature range of SR and FR1 could keep from 650 to $881^{\circ} \mathrm{C}$ when increased inert support recycle rate from 6 to $30 \mathrm{~mol} \mathrm{Fe} / \mathrm{mol} \mathrm{CH}_{4}$. Secondly, the temperature range of $\mathrm{AR}$ and FR2 gradually moved to low temperature region as the inert supply recycle rate increased, which means the decrease of temperature difference between AR and FR1. A more intuitive represent can be seen from Fig.7 that shows the temperature difference between AR and FR1 as a function of inert support recycle rate. Generally, the temperature difference decreased as the inert support recycle rate increased. This can be easily explained by the specific heat capacity formula that inert support recycle rate is inversely proportional to temperature difference. Although, theoretically, a smaller temperature difference between reactors can make the system operate more steadily, in practice, the increase of the inert support recycle rate might also lead to the increase of fluidized gas flow and the size of reactors. Therefore, it is necessary to select a suitable inert support recycle rate considering the requirement above.

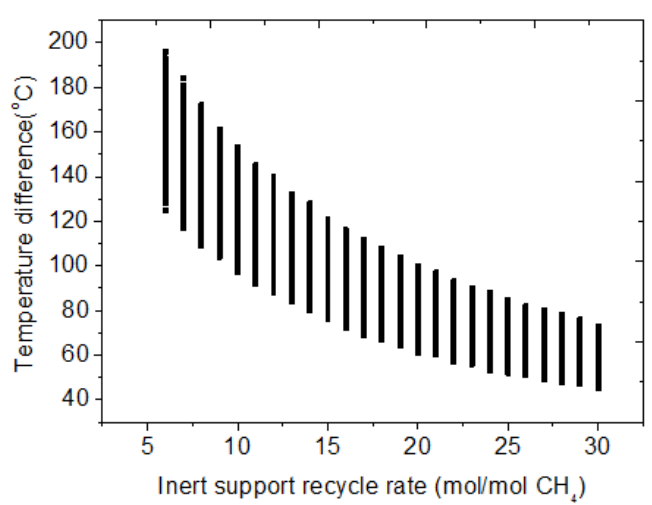

Fig. 7. The temperature difference between $A R$ and FR as a function of inert support recycle rate. 
In addition, it also can be seen from Fig. 6 that the influence of operating region on the inert support recycle rate was not obvious in this case, and a more detailed analysis combined with the variation of oxygen carrier recycle rate will discuss blow..

\subsection{Influence of oxygen carrier recycle rate on operating range}

Eq.13 shows the net reaction occurred in the FR, and the stoichiometry of $\mathrm{CH} 4$ and $\mathrm{Fe}_{2} \mathrm{O}_{3}$ is 1: 4. So the discussion about the oxygen carrier recycle rate first centered around 4 mol Fe/mol CH4 . Fig. 8 shows the $\mathrm{CO}_{2}$ yield and the $\mathrm{H}_{2} / \mathrm{CH}_{4}$ conversion rate $\gamma$ as a function of oxygen carrier recycle rate. As can be seen from blue line, when the oxygen carrier recycle rate less than even equal $4 \mathrm{~mol} \mathrm{Fe} / \mathrm{mol} \mathrm{CH}_{4}$, the reducing gas still unable to be fully oxidized to $\mathrm{CO}_{2}$ and $\mathrm{H}_{2} \mathrm{O}$, since the reaction reduced $\mathrm{Fe}_{3} \mathrm{O}_{4}$ to $\mathrm{FeO}$ (Eq. 4-6) in FR1 is a reversible reaction. The $\mathrm{CO}_{2}$ yield can reach to $99.99 \%$, until the oxygen carrier recycle rate is greater than about $4.5 \mathrm{~mol} \mathrm{Fe} / \mathrm{mol} \mathrm{CH}_{4}$

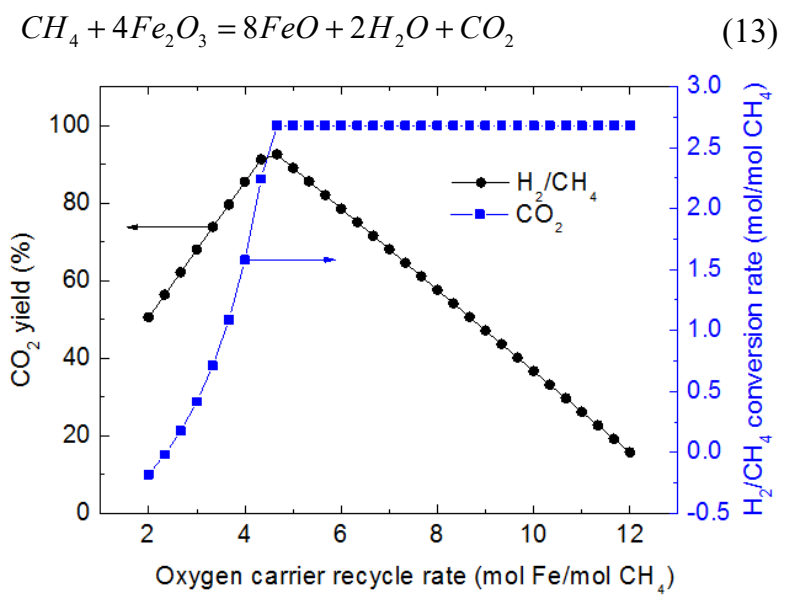

Fig.8. The $\mathrm{CO}_{2}$ yield and the $\mathrm{H}_{2} / \mathrm{CH}_{4}$ conversion rate $\gamma$ as a function of oxygen carrier recycle rate.

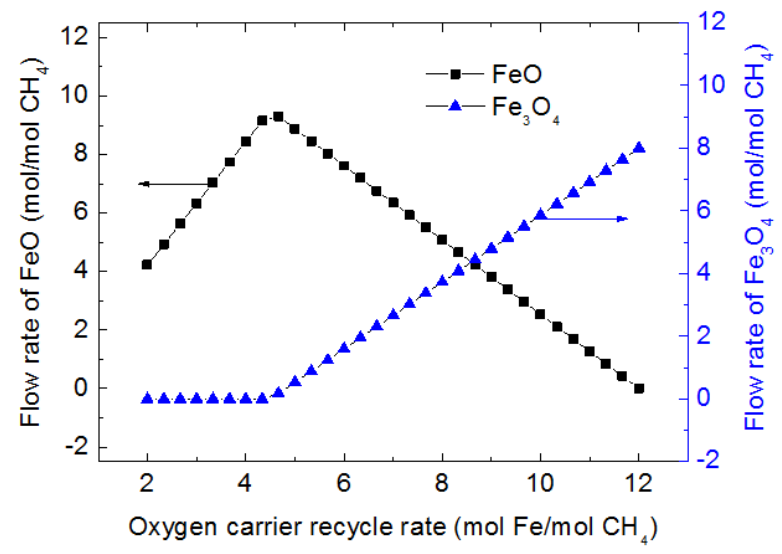

Fig.9. The flow rate of $\mathrm{FeO}$ and $\mathrm{Fe}_{3} \mathrm{O}_{4}$ at the inlet of the $\mathrm{SR}$ as a function of oxygen carrier recycle rate.

The $\mathrm{H}_{2} / \mathrm{CH}_{4}$ conversion rate $\gamma$ as a function of oxygen carrier recycle rate also can be seen from the black line of Fig.8. The $\mathrm{H}_{2} / \mathrm{CH}_{4}$ conversion rate $\gamma$ increased first at low oxygen carrier recycle rate and then decreased after passing through a maximum (about $4.5 \mathrm{~mol} \mathrm{Fe} / \mathrm{mol} \mathrm{CH}_{4}$ ). As we know, a major parameter which influences the $\mathrm{H}_{2} / \mathrm{CH}_{4}$ conversion rate is the flow rate of $\mathrm{FeO}$ going from the FR1 to SR. Fig.9 shows the flow rate of iron oxides at the inlet of the SR as a function of oxygen carrier recycle rate. Apparently, similar tendency can be found between the flow rate of $\mathrm{FeO}$ and the $\mathrm{H}_{2} / \mathrm{CH}_{4}$ conversion rate. Firstly, it is found that the flow rate of $\mathrm{FeO}$ increases with the increase of oxygen carrier recycle rate in the range of 2-4.5 mol $\mathrm{Fe} / \mathrm{mol} \mathrm{CH} 4$, but at higher oxygen carrier recycle rate, the flow rate of $\mathrm{FeO}$ decreases as the oxygen carrier recycle rate increases. This is because at the range of $2-4.5 \mathrm{~mol} \mathrm{Fe} / \mathrm{mol}$ $\mathrm{CH} 4$, the oxygen carrier recycle rate is less than stoichiometric, which means that the amount of reducing gas is enough to convert the oxygen carrier to $\mathrm{FeO}$, and the flow rate of $\mathrm{FeO}$ is determined by the oxygen carrier recycle rate. However, as the oxygen carrier recycle rate exceeds stoichiometric, most of oxygen carrier can only be reduced to $\mathrm{Fe} 3 \mathrm{O} 4$ for the insufficient reducing gas, even no $\mathrm{FeO}$ can be found when the oxygen carrier recycle rate increased to $4.5 \mathrm{~mol} \mathrm{Fe} / \mathrm{mol} \mathrm{CH}_{4}$.

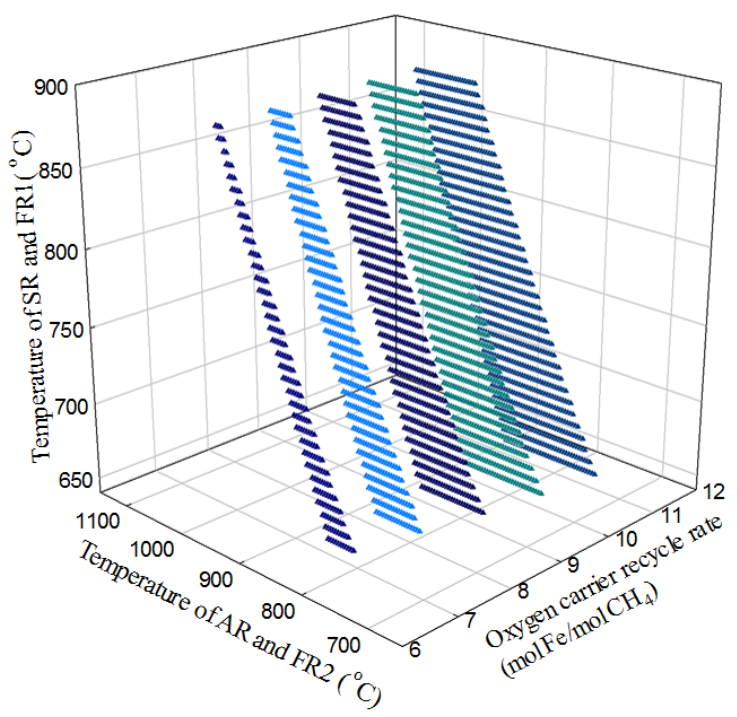

Fig.10. The operating region as a function of oxygen carrier recycle rate and the temperature of $A R$ and $F R$.

Through the analysis above, if only focus on the $\mathrm{CO}_{2}$ yield and the $\mathrm{H}_{2} / \mathrm{CH}_{4}$ conversion rate $\gamma$, the oxygen carrier recycle rate should be operated from 4.5 to $12 \mathrm{~mol} \mathrm{Fe} / \mathrm{mol}$ $\mathrm{CH}_{4}$, and the less oxygen carrier recycle rate in this range, the more $\mathrm{H}_{2} / \mathrm{CH}_{4}$ conversion rate $\gamma$ can be obtain. Based on the operating range of oxygen carrier recycle rate discussed 
above, the influence of oxygen carrier recycle rate on the heat-integrated of four reactors is shown in Fig.10. The detail of the operating parameters can reference $\mathrm{T} 2$ showed in Table 3. It can be observed that the operating region have a strong increase as the oxygen carrier recycle rate increased. This is because as the increase of oxygen carrier recycle rate, the flow rate of unreacted $\mathrm{Fe}_{2} \mathrm{O}_{3}$ entered from FR2 to FR1 increases, which means more exothermic reaction $\mathrm{Fe}_{2} \mathrm{O}_{3}-$ $\mathrm{Fe}_{3} \mathrm{O}_{4}$ occurred in FR1, and therefore replenishes some heat demanded for FR1. From another point of view, it can be seen that part of heat value of $\mathrm{CH}_{4}$ was sacrificed to heat FR1. This can also explain why the $\mathrm{H}_{2} / \mathrm{CH}_{4}$ conversion rate $\gamma$ decreased as the oxygen carrier recycle rate increased.

In sum, although the $\mathrm{H}_{2} / \mathrm{CH}_{4}$ conversion rate $\gamma$ is the highest when oxygen carrier recycle rate operating under 4.5 $\mathrm{mol} \mathrm{Fe} / \mathrm{mol} \mathrm{CH}_{4}$, an operational range of the oxygen carrier recycle rate between 7 and $8 \mathrm{~mol} \mathrm{Fe} / \mathrm{mol} \mathrm{CH}_{4}$ is recommended for more extensive operating region and relative higher $\mathrm{CH}_{4} / \mathrm{H}_{2}$ ratio can be obtain.

\subsection{Formula fitting of operating regions}

From the above analysis, it is clear that there are at least four factors that together determine whether the system can meet the operating criteria. Therefore, it is necessary to set up a fitting formula to describe the operating region based on those factors, which can help to decide the operating condition of system, no matter for experiment or simulation.

The operating region under particular oxygen carrier recycle rate and inert support recycle rate can be expressed by determining the equation of boundary lines $\mathrm{L}_{13}, \mathrm{~L}_{24}$, as can be seen from Fig.11. Point1, 3 and 2, 4 determined the equation of $\mathrm{L}_{13}, \mathrm{~L}_{24}$ separately. In addition, $\mathrm{y}=650$ and $y=881$ was selected as auxiliary line, for the surface of the operational region can be easily calculated by those four points. Therefore, numerical fitting data can be obtained by recorded the slope and intercept of boundary lines $\mathrm{L}_{13}, \mathrm{~L}_{24}$ under different oxygen carrier recycle rate and inert support recycle rate. The test cases used in the present study are summarized in Table 2.

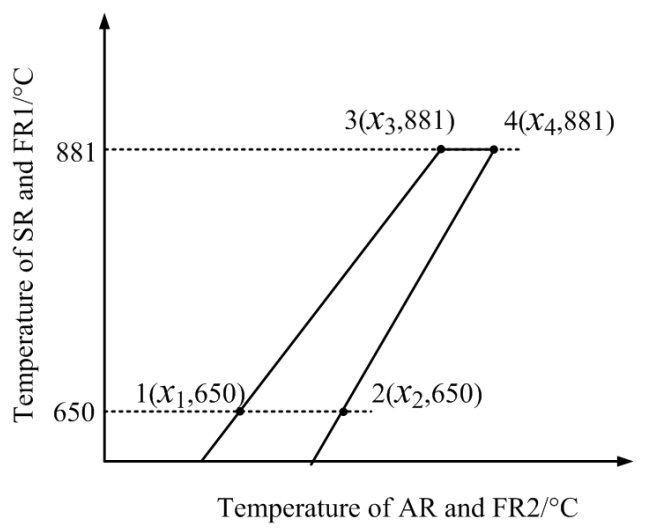

Fig.11. Schematic diagram of the operating region.
Apparently, the precision of the coordinates of point 1-4 have a strong influence on the performance of the fitting formula. Therefore, in order to obtain more precise coordinates of point1-4, a more method was carried out from aspect of ex-endothermic of reactors. For example, Fig. 12 shows the variation of heat release of AR and FR1 as the temperature of AR increase. The temperature of SR was set at $650^{\circ} \mathrm{C}$. Heat release of SR and FR2 do not show in Fig. 12 for both of them are exothermic process. Clearly, the abscissa of "a" and "b" are just the exact value of $\mathrm{x}_{1}$ and $\mathrm{x}_{2}$ shown in Fig. 11 for both AR and FR1 are exothermic with this range. However, the calculated points " $a_{1}$ " and " $\mathrm{a}_{2}$ " can only close but cannot replace the exact point "a". So further precision was obtained by calculated the intersection of abscissa and the line determined by points " $a_{1}$ " and " $a_{2}$ ". In this way, all the accurate abscissa of point 1-4 in Fig.11 can be obtained in any case, which built a solid foundation for fitting formula.

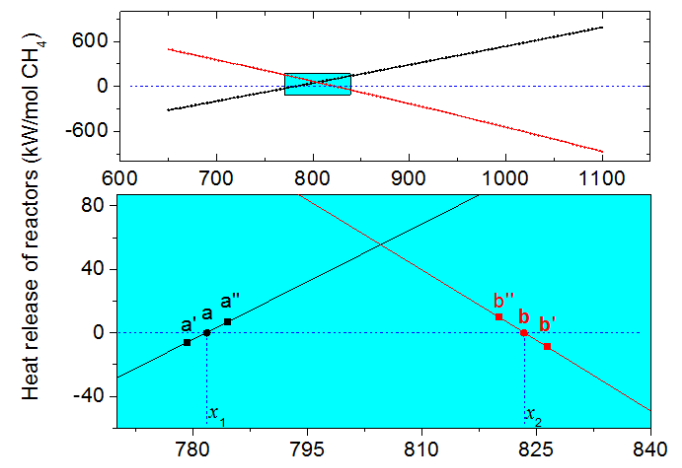

Fig.12. Schematic diagram of the calculation method.

$$
\begin{aligned}
& a_{13}(x, y)=0.8923+0.038 \ln (x)+0.5720 \ln (y) / y \\
& b_{13}(x, y)=0.6161+0.1527 \ln (x)+1.591 \ln (y) / y \\
& a_{24}(x, y)=51.82+612.5 \exp (-x / 10.61) \cdot \exp (-y / 10.61) \\
& b_{24}(x, y)=365.2+137.2 \ln (x)-146.6 \ln (y)
\end{aligned}
$$

Where, $x$ represents the oxygen carrier recycle rate and $\mathrm{y}$ represent the inert support recycle rate.

$$
\begin{gathered}
T_{A R} \in\left[\frac{T_{S R}-\mathrm{b}_{13}(x, y)}{a_{13}(x, y)}, \frac{T_{S R}-\mathrm{b}_{24}(x, y)}{a_{24}(x, y)}\right] \\
T_{S R} \in[650,881], x \in[7,12], y \in[4,40]
\end{gathered}
$$

1stOpt, one of the most popular fitting formula software produced by 7D-Soft High Technology Inc, have a powerful computational ability on the nonlinear multivariate fitting. Four two-parameter fitting formula is calculated by $1 \mathrm{stOpt}$ to approximately the slope and intercept of boundary lines $\mathrm{L}_{13}, \mathrm{~L}_{24}$, as can be seen from Eq14-17. Every fitting formula has only three constants to ensure the fitting formula simply. Both the optimization method of Levenberg-Marquardt and Universal Global Optimization was used in this fitting process. Some parameters assessed the fitting formula is showed in Table 4 . As can be seen that 
small Root Mean Square Error of four fitting formulas can be obtained and the correlation coefficient can reach to at least 0.995 , which have a good performance on the fitting precision.

Table 4. Main parameters for fitting formula.

\begin{tabular}{|l|r|r|r|r|}
\hline Parameter & \multicolumn{1}{|c|}{$\boldsymbol{a}_{\mathbf{1 3}}$} & $\boldsymbol{a}_{\mathbf{2 4}}$ & \multicolumn{1}{c|}{$\boldsymbol{b}_{\mathbf{1 3}}$} & \multicolumn{1}{c|}{$\boldsymbol{b}_{\mathbf{2 4}}$} \\
\hline $\begin{array}{l}\text { RMSE(Root } \\
\text { Mean Square } \\
\text { Error) }\end{array}$ & 0.00385 & 0.00714 & 2.93489 & 4.43834 \\
\hline $\begin{array}{l}\text { SSE (Sum of } \\
\text { Squares for } \\
\text { Error) }\end{array}$ & 0.01097 & 0.0378 & 6374.05 & 14577.1 \\
\hline $\begin{array}{l}\text { R } \\
\text { (Correlation } \\
\text { Coefficient) }\end{array}$ & 0.99523 & 0.99792 & 0.99814 & 0.99885 \\
\hline $\begin{array}{l}\text { DC } \\
\text { (Coefficient } \\
\text { of } \\
\begin{array}{l}\text { Determination } \\
\text { ) }\end{array}\end{array}$ & 5 & 1 & 5 & 5 \\
\hline
\end{tabular}

Another formula was given based on those four fitting formulas. As can be seen from Eq. 18 that the range of TAR can be determined when given a certain value of the TSR, oxygen carrier recycle rate $\mathrm{x}$ and the inert support recycle rate $y$. The applicable range of the formula is extensive for the wide domain of TAR, $x$ and $y$. The formula gives a good description of the operating region and provides certain references for the selection of the operating condition.

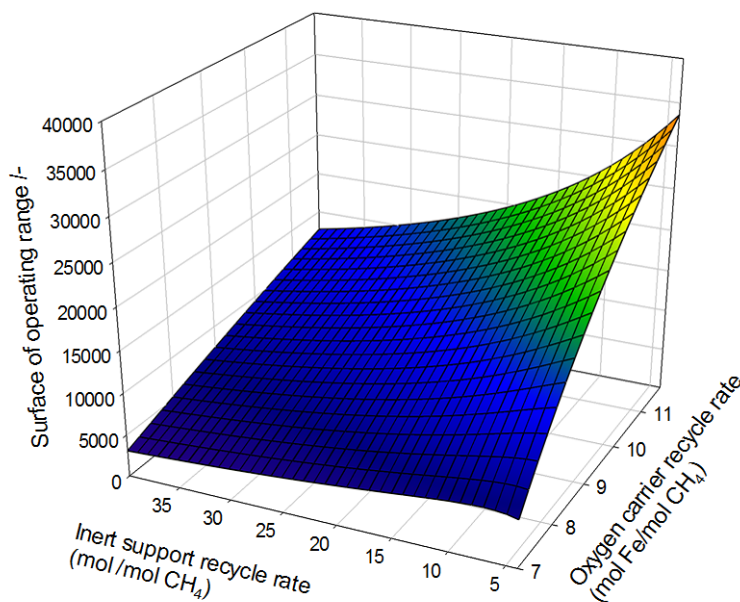

Fig.13. The area of the operating region as a function of the inert support recycle rate and the oxygen carrier recycle rate.

\section{Conclusions}

A simulation of a chemical looping hydrogen generation process using compact fluidized bed as fuel reactor, which can deeply reduce iron oxides to $\mathrm{FeO}$ while simultaneously fully converting the reducing gas to $\mathrm{CO}_{2}$ and $\mathrm{H}_{2} \mathrm{O}$, has been carried out in this paper. The operational parameters of the system were set by specifying the oxygen carrier recycle rate, inert support recycle rate and temperature of reactors, and from this a suitable operating range of system, which not only gives satisfactory performance but can also be fully heat balance among reactors, has been conceived. In addition, a three-parameter fitting formula for the operating condition of CLHG system was proposed in this study. It can provide reference for the selection of operating condition, no matter for experiment or simulation. In more detail, the following conclusions can be drawn:

The low limit of the system temperature is $650^{\circ} \mathrm{C}$, or else unexpected reaction will occur in reactors. In consideration of the iron oxygen melting point, the up limit of FR1 was set at $1000{ }^{\circ} \mathrm{C}$ and 1100 of $\mathrm{AR}$.

The system cannot reach to heat balance among reactors without mixing inert support into oxygen carrier, since FR2 is a strong endothermic reaction. Inert support can carry the heat quantity from the high exothermic process reaction occurred in AR to FR1. And, the increase of inert supper recycle rate have can help reduce the temperature difference between AR and FR1, which can make sure the system operated steadily.

In addition, the operating range of system had a strong increase as the oxygen carrier recycle rate increased. The trend is because more $\mathrm{Fe}_{2} \mathrm{O}_{3}$ reacted with $\mathrm{CH}_{4}$ in $\mathrm{FR} 1$, which released more heat quantity for endothermic reaction in FR1. Nevertheless, the consumption of $\mathrm{CH}_{4}$ will reduce the $\mathrm{CH}_{4} / \mathrm{H}_{2}$ ratio. Therefore, the oxygen carrier recycle rate operating between $150 \%$ and $200 \%$ was recommended.

Moreover, the fitting formula had a high fitting accuracy, validated against as many cases as possible, and for as wide a range of recycle rate of oxygen carrier and inert support.

Further work will focus on hot-condition experimental study of CLHG. Such data will be central to operating and controlling the hot rig in the future.

\section{References}

1. P Tobias, B Johannes, K Proll, et al. Syngas and a separate nitrogen/argon stream via chemical looping reforming - A $140 \mathrm{~kW}$ pilot plant study. Fuel. 89 (6), 1249-1256 (2010)

2. W Carl-Jochen. J. Hydrogen energy - Abundant, efficient, clean: A debate over the energy-system-ofchange. International Journal of Hydrogen Energy. 34 (14), S1-S52 (2009)

3. M Tobias, L Anders, C Pyeong-Seok. The use of iron oxide as an oxygen carrier in chemical-looping combustion of methane with inherent separation of $\mathrm{CO}_{2}$. Fuel. 80 (13), 1953-1962 (2001)

4. A, Alberto, M Tobias, L Anders, et al. The use of iron oxide as oxygen carrier in a chemical-looping reactor. Fuel. 86 (7-8), 1021-1035 (2007)

5. M Tobias, L Anders. Multicycle reduction and oxidation of different types of iron oxide particles - 
Application to chemical-looping combustion. Energy \& Fuels. 18 (3), 628-637 (2004)

6. H Mohammad, D Lasa. Chemical-looping combustion (CLC) for inherent $\mathrm{CO}_{2}$ separations-a review. Chemical Engineering Science. 63 (18), 4433-4451(2008)

7. A Hazzim, D, Wan. Hydrogen production by methane decomposition: A review. International Journal of Hydrogen Energy. 35 (3), 1160-1190 (2010)

8. C Paolo; L Giovanni, M Alberto, et al. Three-reactors chemical looping process for hydrogen production. International Journal of Hydrogen Energy. 33 (9), 2233-2245 (2008)

9. C Jason, B Christopher, M Christoph, et al. Clean hydrogen production and electricity from coal via chemical looping: Identifying a suitable operating regime. International Journal of Hydrogen Energy. 34 (1), 1-12 (2009)

10. L Fan, F Li, Ramkumar S. Utilization of chemical looping strategy in coal gasification processes. Particuology. 6 (3), 131-142 (2008)

11. G Nirmal, R Donald, R Marc. Hydrogen production from coal using coal direct chemical looping and syngas chemical looping combustion systems: Assessment of system operation and resource requirements. International Journal of Hydrogen Energy. 34 (6), 2606-2615 (2009)

12. W Xiang, S Chen, Z Xue, et al. Investigation of coal gasification hydrogen and electricity co-production plant with three-reactors chemical looping process. International Journal of Hydrogen Energy. 35 (16), 8580-8591 (2010)

13. F Li, L Zeng, V Luis, et al. Syngas Chemical Looping Gasification Process: Bench-Scale Studies and Reactor Simulations. Aiche Journal. 56 (8), 2186-2199(2010)

14. J Erik, M Tobias, L Anders. Thermal Analysis of Chemical-Looping Combustion. Chemical Engineering Research and Design 84 (9), 795-806 (2006)

15. M Tobias, L Anders. Capture of $\mathrm{CO}_{2}$ using chemicallooping combustion. First Biennial Meeting of the Scandinavian-Nordic Section of the Combustion Institute, Göteborg, Sweden, 2001.

16. J Yang, N Cai, Z Li. Hydrogen production from the steam-iron process with direct reduction of iron oxide by chemical looping combustion of coal char. Energy \& Fuels. 22 (4), 2570-2579 (2008)

17. G Puneet, V Luis, L Fan. Syngas redox (SGR) process to produce hydrogen from coal derived syngas. Energy \& Fuels. 21 (5), 2900-2908 (2007)

18. Z Xue, S Chen, D Wang, et al. Design and Fluid Dynamic Analysis of a Three-Fluidized-Bed Reactor System for Chemical-Looping Hydrogen Generation. Industrial \& Engineering Chemistry Research 51 (11), 4267-4278 (2012) 